\title{
Lactante mayor con tumor cerebral con diseminación intrarraquídea
}

\section{A brain tumor with intraspinal spread in an infant}

\author{
Marcial Anaya-Jara, ${ }^{1}$ Gilberto Gómez-Garza, ${ }^{2}$ Yadira Gandhi-Mata, ${ }^{3}$ Cecilia Ridaura-Sanz ${ }^{4}$
}

\section{RESUMEN}

Niña de 2 años 6 meses, originaria del medio rural de Veracruz. Sin antecedentes heredofamiliares relacionados con su enfermedad. Nació a las 32 semanas por ruptura prematura de membranas, permaneció 29 días hospitalizada por prematurez. Su desarrollo psicomotor fue adecuado hasta los 10 meses de edad cuando tuvo crisis convulsivas en dos ocasiones relacionadas con un cuadro febril e infección de las vías aéreas superiores. Fue valorada por un médico pediatra en su lugar de origen, quien solicitó una tomografía de cráneo en la que se detectó hidrocefalia. En ese estudio no se reportó alguna lesión ocupativa intracraneal o la causa de la hidrocefalia.

A los 11 meses de edad, en el Hospital de Río Blanco, Veracruz, se le colocó una válvula de derivación ventrículo peritoneal. Posterior a esto logró la deambulación hasta los 20 meses de edad. A los 24 meses tuvo regresión de sus habilidades: dejó de caminar debido a la disminución progresiva en la fuerza en las extremidades inferiores que le impidió la bipedestación. En la tomografía y resonancia magnética de cráneo (estudios externos al Instituto Nacional de Pediatría) a los 28 meses de edad se detectó un tumor intracraneal localizado por encima de la silla turca (hipotálamo).

En la exploración física efectuada a su ingreso al Instituto Nacional de Pediatría se le encontró fuerza 5 de 5 en las extremidades superiores y 2 de 5 en las extremidades inferiores, con movimientos involuntarios en estas últimas, disminución del tono muscular, los reflejos de estiramien-

\footnotetext{
${ }^{1}$ Adscrito del Departamento de Neurocirugía.

${ }^{2}$ Adscrito al Departamento de Radiología e imagen.

${ }^{3}$ Residente de Patología pediátrica.

${ }^{4}$ Adscrita Departamento de Anatomía patológica.

Instituto Nacional de Pediatría, Ciudad de México.

Recibido: 29 de marzo 2019

Aceptado: 5 de abril 2019

Correspondencia

Cecilia Ridaura Sanz

cridaura@gmail.com

Este artículo debe citarse como Anaya-Jara M, Gómez-Garza G, GandhiMata Y, Ridaura-Sanz C. Lactante mayor con tumor cerebral con diseminación intrarraquídea. Acta Pediatr Mex 2019;40(3): 148-153.
} 
to muscular disminuidos en las extremidades inferiores y normales en las superiores: lograba mantener la sedestación apoyándose con las manos, pero no conseguía la bipedestación. Las respuestas plantares eran indiferentes. Sin control de esfínteres. En ninguna de las extremidades inferiores tenía sensibilidad al dolor, incluso la niña se llegó a lesionar ella misma los genitales y piernas por no sentirlas.

Ante la sospecha de otra lesión, en la valoración por parte de los especialistas del servicio de Neurocirugía se efectuó otra resonancia magnética del neuroeje, a nivel medular, por la afectación en ambas extremidades inferiores y la integridad de las extremidades superiores.

Se tomaron marcadores tumorales: alfafetoproteína, hormona gonadotropina coriónica sérica y en el líquido cefalorraquídeo, con reportes normales. Se descartaron alteraciones en el eje hipotálamo hipofisiario. El resto de los estudios de laboratorio se reportaron normales.

En la cirugía neurológica se le efectuó una craneotomía frontotemporal derecha y se le tomó una biopsia de la lesión; permaneció cinco días en terapia intensiva para cuidados posoperatorios, requirió tratamiento para diabetes insípida. La biopsia no fue concluyente por lo que se reintervino con reapertura de la craneotomía 9 días después.

Con el resultado histopatológico definitivo se turnó para tratamiento por parte de los especialistas en Oncología quienes le indicaron radioterapia (36 Gy craneoespinal y 45 Gy al sitio primario intracraneal) y quimioterapia con temozolamida por vía oral.

La paciente fue dada de alta del hospital, con seguimiento en la consulta externa de Neurocirugía, Oncología y Radioterapia. Dos meses más tarde, al acudir a la consulta de Neurocirugía se observó dehiscencia de la herida quirúrgica frontotemporal derecha con exposición del hueso del cráneo, se tuvo que internar de nuevo y hacer un aseo quirúrgico con anestesia. En los cultivos de la herida quirúrgica dehiscente se aisIaron Klebsiella oxytoca BLEE y Staphylococcus aureus. Los médicos del servicio de Infectología le indicaron ceftriaxona, dicloxacilina y posteriormente ertapenem.

Nueve días después se le hizo un nuevo aseo quirúrgico por persistencia de secreción por la herida, con hallazgo de pus epidural. Además, se reportaron hifas y blastoconidias en la orina, agregándose fluconazol al tratamiento.

Cuatro días después de la última cirugía resultó con neumonía con una consolidación parahiliar derecha e infiltrado parahiliar izquierdo, insuficiencia respiratoria que requirió intubación y apoyo mecánico ventilatorio. Se le detectó leucopenia progresiva incluso de 900 leucocitos y 5 mil plaquetas. Ante la mala evolución clínica se efectuó el cambio de antibióticos: piperacilinatazobactam.

Evolucionó mal, con síndrome de dificultad respiratoria grave Ilegando a saturar sólo 43\% de oxemia. Falleció 16 días después de la última cirugía.

\section{COMENTARIO CLÍNICO \\ Marcial Anaya Jara}

La paciente tuvo inicialmente un cuadro clínico de hipertensión endocraneal secundario a hidrocefalia, con crisis convulsivas y retroceso en hitos del desarrollo, déficits motor y sensitivo progresivos de las extremidades inferiores, hasta establecerse una afección medular completa, lo que indicaba una patología con localización intracraneal y otra de médula espinal. Al parecer, en la tomografía de cráneo (efectuada fuera del INP) no se identificó alguna causa que explicara, 
inicialmente, los síntomas hasta que se realizó la resonancia magnética, en la que se identificó una lesión ocupativa en la región supraselar y otra lesión en torno del canal medular torácico sugerentes de un tumor intracraneal primario, con metástasis, que condicionó la compresión medular.

Entre los tumores intracraneales más frecuentes que originan metástasis están: glioblastoma multiforme, ependimoma, meduloblastoma y el papiloma de plexos coroides. Estas metástasis intradurales extramedulares, que se originan de tumores intracraneales, se denominan metástasis "en gota" o (drop metastases) y pueden diseminarse por vía hematógena o siguiendo la circulación del líquido cefalorraquídeo: son metástasis muy raras que afectan a $0.1-0.4 \%$ de los pacientes con cáncer. ${ }^{1}$

La evolución de la paciente fue tórpida, característica de los procesos tumorales, con dehiscencia de la herida quirúrgica secundaria al tratamiento coadyuvante (radioterapia y quimioterapia) con infección agregada, leucopenia severa y neumonía intrahospitalaria que le causó la muerte.

\section{COMENTARIO RADIOLÓGICO}

\section{Gilberto Gómez Garza}

En un estudio externo de resonancia magnética cerebral se detectó una tumoración supraselar lobulada dependiente del quiasma óptico con morfología en $\mathrm{H}$ y reforzamiento intenso, que se acompañaba de un reforzamiento leptomeníngeo con extensión al conducto raquídeo. Figura 1

Con esos datos se puede incluir al astrocitoma pilomixoide en el diagnóstico radiológico diferencial de tumores quiasmáticos que se diseminan al canal raquídeo. ${ }^{2}$

\section{COMENTARIO ANATOMOPATOLÓGICO}

\section{Yadira Gandhi Mata, Cecilia Ridaura Sanz}

El estudio de la tumoración extirpada mostró una neoplasia glial, con patrón fusiforme de abundante material mixoide y células alargadas de disposición perivascular. No se encontraron fibras de Rosenthal ni cuerpos granulares. Con estas características se estableció el diagnóstico de astrocitoma pilomixoide (grado II de la OMS). Figuras 2 y 3

En el estudio postmortem en la región parietal derecha se encontró una herida quirúrgica suturada, de bordes tumefactos y eritematosos, con ausencia quirúrgica de hueso temporal, pero sí una derivación ventricular en el sitio habitual y herida quirúrgica transversal en el abdomen. En el sistema nervioso central, la duramadre estaba engrosada con material herrumbroso de hemorragia antigua y tejido fibroso vascularizado con exudado inflamatorio mononuclear. La porción dorsal del encéfalo mostró circunvoluciones atróficas. Por la superficie ventral se identificó la lesión neoplásica mal delimitada, de aspecto gelatinoso, que abarcaba parte del cerebelo, hasta los cuerpos mamilares. En los cortes coronales del encéfalo se apreció una dilatación ventricular y un tumor de color blanquecino que abarcaba desde los ganglios basales hasta el cerebelo y afectaba el parénquima a nivel del hipocampo (Figuras 4 y 5). En el canal raquídeo, la duramadre estaba abombada y en los cortes seriados las meninges se encontraron engrosadas, con un tumor en el espacio subaracnoideo que comprimía la médula espinal. Figura 6

En el resto de los órganos se encontraron: pulmones aumentados de peso, congestivos con émbolos de médula ósea en las arterias pulmonares intraparenquimatosas y daño alveolar difuso, con edema y membras hialinas adosadas a la pared alveolar pequeñas. Además, bronquiolitis necrosante en ambos pulmones y el hígado 


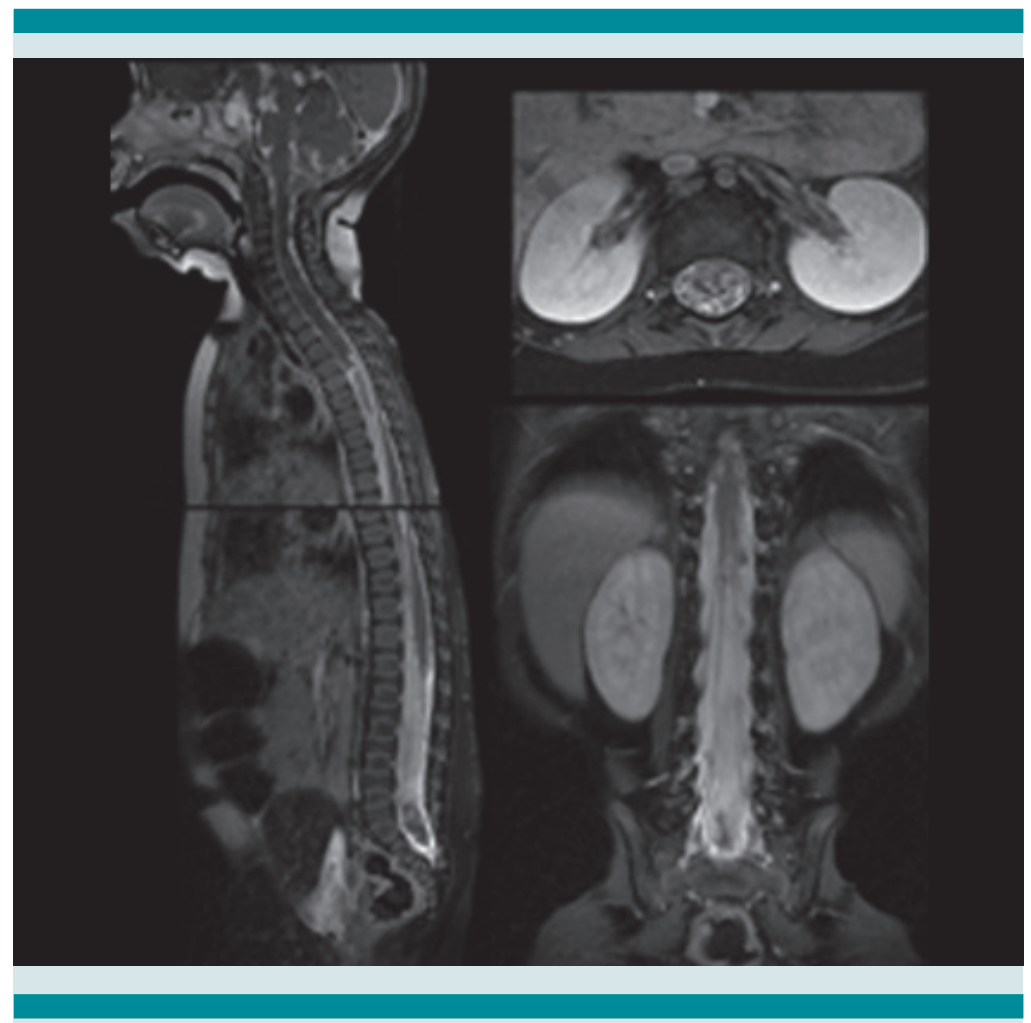

Figura 1. Imágenes de resonancia magnética del neuroeje ponderadas en T1 poscontraste (gadolinio) donde se observa una masa supraselar y un extenso reforzamiento leptomeníngeo y de los espacios subaracnoideos con algunas imágenes nodulares adheridas a la superficie de la médula espinal. El diagnóstico de sospecha fue: astrocitoma pilomixoide.

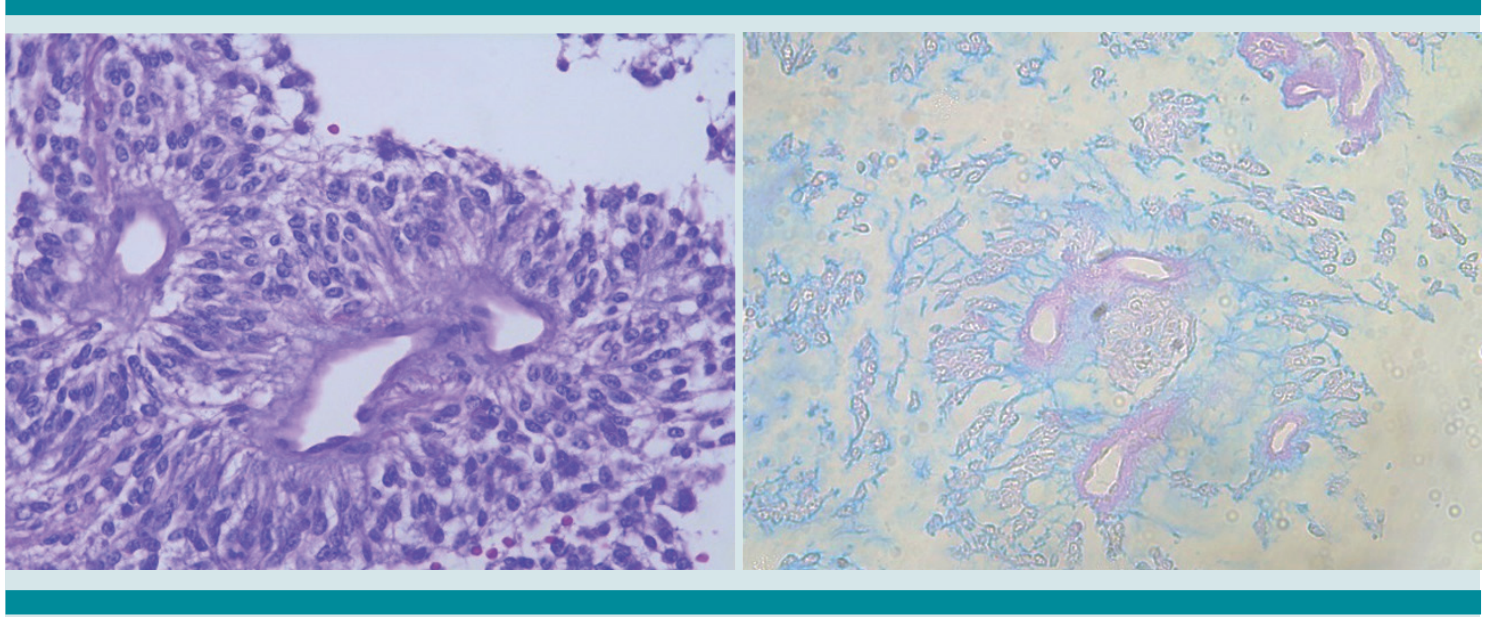

Figuras 2 y 3. Astrocitoma pilomixoide, lesión pinocítica con prolongaciones bipolares dispuestas alrededor de pequeños inmersos en estroma mucinoso (material azul en la Figura 2). 


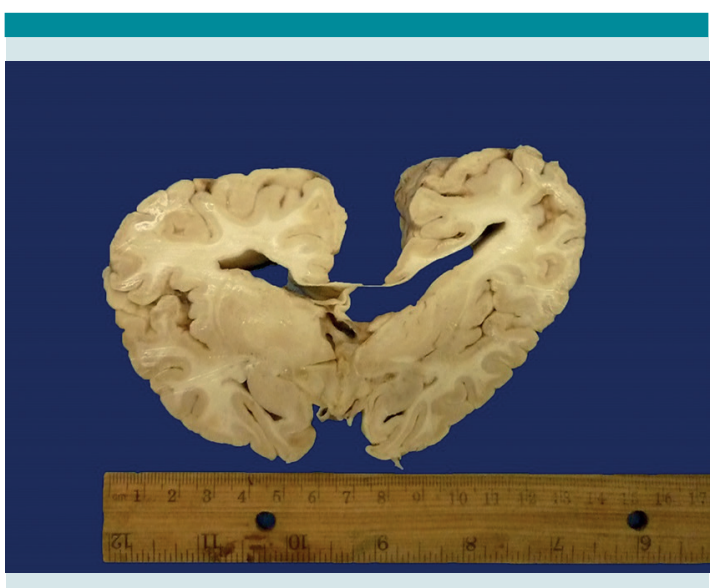

Figura 4. Infiltración intraparenquimatosa a nivel del hipocampo y en la periferia de los ganglios basales hasta el cerebelo, el aspecto y consistencia de esta lesión es esponjoso.

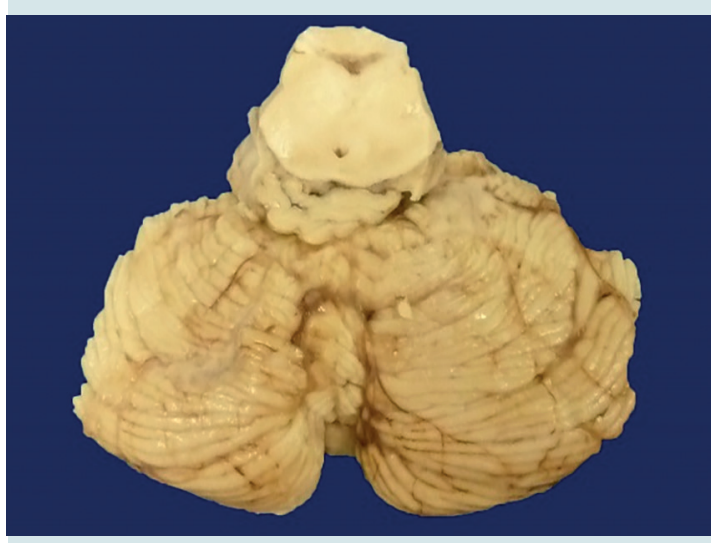

Figura 5. Lesión tumoral a nivel de los pedúnculos cerebrales.

aumentado de peso de color amarillento, con esteatosis de gota gruesa en más de 30\% del parénquima (imágenes no mostradas).

\section{DISCUSIÓN}

Este caso ejemplifica las características histológicas clínicas de un tumor pediátrico poco

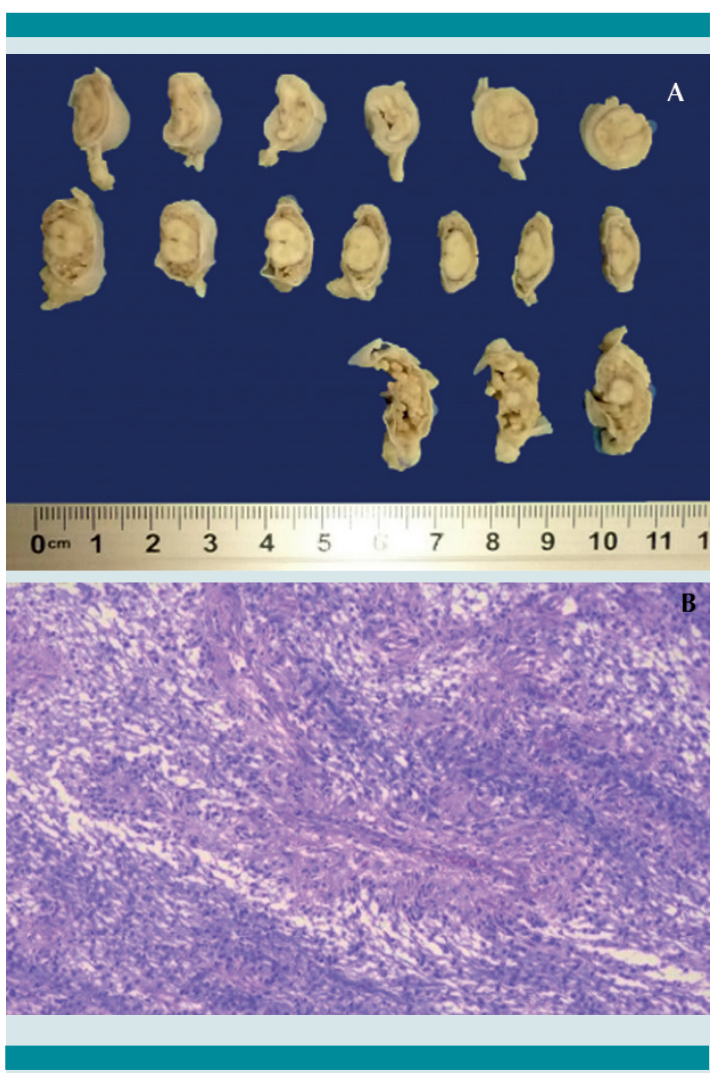

Figura 6. A. Cortes transversales de la médula espinal con tumor subaracnoideo. B. Imagen de la histología del tumor con el estroma mixoide con la disposición radial de las células neoplásicas.

conocido. $^{3,4} \mathrm{El}$ tumor del sistema nervioso central, ahora denominado astrocitoma pilomixoide, inicialmente se describió como una neoplasia que ocurría en niños pequeños, con características histológicas que lo diferenciaban del astrocitoma pilocítico clásico. ${ }^{2}$ Esta lesión fue revisada y publicada en 1996 con el estudio de 18 astrocitomas pilocíticos; se concluyó que por sus características histológicas y clínicas peculiares y, por su aspecto histológico, se denominaba astrocitoma pilomixoide.

A partir de 2007 se incluyó en la clasificación de tumores del sistema nervioso central de la Organización Mundial de la Salud, considerado 
provisionalmente como una variante maligna del astrocitoma pilocitico clásico, que tiene mayor potencial de crecimiento y recidiva y un comportamiento infiltrante; por esto la OMS lo clasifica grado II, que implica peor pronóstico y la posibilidad de evolución hacia un glioma de mayor grado.

Desde el punto de vista histológico se caracteriza por la existencia de un estroma mixoide prominente y un arreglo angiocéntrico de células bipolares mono morfas, típicamente sin fibras de Rosenthal ni cuerpos granulares.

Con estas características histológicas se han empezado a acumular experiencias que parecen indicar que se trata de un padecimiento específico y no sólo de una variante del astrocitoma pilocítico convencional. La mayor parte de las publicaciones señalan que el astrocitoma pilo- mixoide ocurre en niños pequeños y tiende a localizarse en el hipotálamo y que, efectivamente, se comporta en forma agresiva. Sin embargo, sigue habiendo controversia en relación con su origen.

\section{REFERENCIAS}

1. Simas A, Sales C, Fragoso M. "Drop metastasis": a rare diagnosis. A case report and review of literature. Galicia Clin. 2017;78(1):23-25.

2. Komotar RJ, et al. Magnetic resonance imaging characteristics of pilomyxoid astrocytoma. Neurol Res. 2008;30:94551. https://doi.org/10.1179/174313208X322806

3. Louis DN, et al. The 2007 WHO Classification of Tumours of the Central Nervous System. Acta Neuropathol 2007;114:97109. https://doi.org/10.1007/s00401-007-0243-4

4. Amatya VJ, et al. Clinicopathological and immunohistochemical features of three pilomyxoid astrocytomas: comparative study with 11 pilocytic astrocytomas. Pathol Int 2009; 59:80-85. https://doi.org/10.1111/j.14401827.2008.02332.x 